\title{
RBEP
}

\section{Programa de Formação Interdisciplinar Superior: um novo caminho para a educação superior*}

\section{Cibele Y. Andrade}

Francisco A. M. Gomes

Marcelo Knobel

Ana Maria A. C. Silva

\section{Resumo}

Apresenta o Programa de Formação Interdisciplinar Superior (ProFIS), curso de nível superior implantado na Universidade Estadual de Campinas (Unicamp) em 2011. Primeiramente, são citados os objetivos e as diretrizes que nortearam a criação do curso - aumento do ingresso de alunos de escolas públicas na universidade e a adoção de um programa de formação geral - e, em seguida, descritos, em linhas gerais, o novo curso, seu currículo e o processo de transferência dos alunos concluintes do ProFIS para os cursos de graduação da Unicamp. Conclui apresentando uma análise sobre o critério de seleção adotado, bem como alguns dados estatísticos que revelam que os propósitos de inclusão social foram plenamente alcançados pela primeira turma matriculada no programa.

Palavras-chave: admissão no ensino superior; política de inclusão social; educação geral; estatísticas educacionais.

*A elaboração deste artigo também contou com a participação dos professores Renato H. L. Pedrosa, Elisabete M. A. Pereira e Lício A. Velloso. 


\section{Abstract \\ Interdisciplinary Higher Education Program: a new way to higher education}

This paper introduces the ProFIS (a portuguese acronym for Interdisciplinary Higher Education Program), an undergraduate course established at Universidade Estadual de Campinas (Unicamp) in 2011. Firstly, we mention the guidelines adopted for the creation of the course, which are the increase of the admission of low-income students, and the adoption of a general education program at the university. Then, we briefly describe the new course, including its curriculum and the mechanism of migration from ProFIS to other undergraduate courses of Unicamp. We conclude presenting the admission process, as well as some statistical data that reveals that the social inclusion aim was fully achieved by the first group of students admitted to the program.

Keywords: higher education admission; social inclusion policy; education; educational statistics.

\footnotetext{
Um professor deve transmitir aos jovens não o saber em si e o conhecimento, mas a sede de saber e de conhecer, assim como o respeito pelos valores do espírito, quer sejam de ordem artística, científica ou moral. Albert Einstein
}

Quando se debate a educação superior brasileira, inúmeras questões surgem a respeito dos caminhos que ela pode vir a tomar. Além da ampliação de vagas no sistema público (incluindo pontos como a criação de novas universidades, a reposição do quadro docente, a melhoria da infraestrutura física e o ensino a distância), surgem, na pauta de discussões, importantes questões referentes à inclusão social, à avaliação e aos mecanismos de ingresso, sempre acompanhadas de debates sobre a qualidade do ensino e a valorização da atividade docente. A estruturação do sistema educacional superior brasileiro levou a uma situação fortemente excludente e a um sistema consideravelmente engessado no que se refere a alternativas para que os alunos desenvolvam diferentes caminhos no ensino superior.

O vestibular representa um funil crítico para os estudantes que desejam ingressar em boas universidades. Na Universidade Estadual de Campinas (Unicamp), por exemplo, as vagas contemplam apenas 6\% dos candidatos inscritos no vestibular. Além disso, a forma de entrada no ensino superior é por curso, obrigando jovens de 17 ou 18 anos a realizarem muito precocemente escolhas de grande implicações para suas vidas. 
Da mesma forma, quando se tornam profissionais, esses jovens devem encarar o competitivo mercado de trabalho com 21 ou 22 anos. Assim, os dados tabulados por Nunes (2011), do Observatório Universitário, a partir de dados do censo de 2000, mostrando que aproximadamente $54 \%$ dos profissionais regulamentados não atuam em suas áreas de formação (nas engenharias esse número sobe para 67\%), não deveriam surpreender.

Para atenuar os efeitos indesejáveis provocados pela escolha precoce da carreira profissional e pela extrema especialização dos cursos de graduação, bem como possibilitar um maior ingresso de alunos de escolas públicas, a Unicamp criou um programa-piloto denominado Programa de Formação Interdisciplinar Superior (ProFIS), voltado exclusivamente, nesse primeiro momento, a alunos egressos de escolas públicas do município de Campinas, cujo propósito é fornecer uma formação geral, de caráter multidisciplinar, que proporcione uma base ampla nas principais áreas do conhecimento, e à formação de cidadãos com visão crítica e social, inserindo o aluno em atividades de cultura geral focadas nas questões sociais, humanas e éticas, para a construção de uma sociedade mais democrática e justa (Unicamp, 2010).

O ProFIS tem como objetivo a ampliação de conhecimentos nas áreas das Ciências Humanas, Artes e Ciências da Natureza, possibilitando a abordagem de problemas científicos de modo integrado, a compreensão da ciência como um modo de olhar o mundo e a compreensão das relações do conhecimento com o mundo do trabalho, tendo em vista uma definição mais segura do campo profissional futuro. Assim, sua estrutura curricular foi organizada com disciplinas básicas dessas grandes áreas do conhecimento humano. Após concluir o curso, os alunos podem ingressar em cursos de graduação da Unicamp sem a necessidade de passar pelo concurso vestibular.

Nas seções a seguir são apresentados os estudos sobre inclusão social e formação geral que nortearam a criação do ProFIS, introduzidas as linhas gerais do programa e feita uma análise do perfil acadêmico e socioeconômico dos candidatos inscritos no processo de seleção do curso, bem como dos alunos ingressantes em 2011.

\section{Inclusão social, ensino superior e o papel da Unicamp}

As políticas públicas de inclusão social têm por escopo minimizar as desigualdades e enfatizar aspectos de promoção da igualdade, do bem-estar e do desenvolvimento social, por meio da constante melhoria da qualidade de vida de todos os cidadãos. As ações podem ser focadas em diversas áreas de interesse da sociedade, e o acesso a um ensino público de nível superior de qualidade é considerado um dos mais eficientes mecanismos para a inclusão social. A implementação dessas políticas forneceu a um número significativo de alunos várias alternativas de acesso à universidade e a cursos tecnológicos e profissionalizantes, entretanto a garantia de acesso não está associada apenas a uma política de ingresso nos cursos. 
Para que seja efetivada a política de inclusão, é fundamental a existência de ações que garantam que os alunos permaneçam na universidade, finalizem seus cursos e sejam inseridos no mercado de trabalho, multiplicando, assim, os conhecimentos e experiências adquiridas. Dessa forma, a implantação de uma nova forma de acesso à universidade deve ser complementada por ações de acompanhamento do aluno desde seu ingresso até sua completa formação e inserção social.

É fato que a vivência e o aprendizado no ensino superior oferecem uma oportunidade real de ascensão socioeconômica ao indivíduo e que qualquer ação que vise implementar mecanismos de correção da desigualdade social deve passar pela expansão da oferta de vagas do ensino superior às camadas menos favorecidas da população. De acordo com Schwartzman (2008), existem duas maneiras de se considerar a questão da inclusão quando o tema é o ensino superior: a primeira, que predomina na discussão brasileira, é a ampliação do acesso através do aumento do número de vagas; a segunda é a criação de políticas de admissão de estudantes.

No que diz respeito à ampliação do acesso, o Censo da Educação Superior de 2009 divulgado pelo Inep (2010) indica um crescimento de 475 mil vagas na educação superior presencial brasileira entre 2001 e 2009. Entretanto, a maior parte dessa expansão ocorreu no ensino privado, que conta hoje com pouco mais de $75 \%$ do total de vagas do País. Um aspecto positivo é o fato de que o acesso à educação superior está apresentando uma mudança no perfil dos alunos: entre 2001 e 2005, verificou-se um aumento de $87 \%$ da presença de não brancos e $67 \%$ da presença de indivíduos que compõem o terceiro, quarto e quinto quintis da distribuição de renda. Contudo, mais uma vez, tal crescimento foi substancialmente maior no ensino privado do que no público, o que acarreta um ônus adicional à parcela economicamente menos favorecida da população.

Fica claro que o ensino superior brasileiro está crescendo e incorporando indivíduos provenientes de setores sociais menos privilegiados. Isto vem ocorrendo de forma independente, ou apenas parcialmente dependente, de políticas deliberadas de inclusão. Certamente, no setor privado, o aumento de estudantes de baixa renda é um reflexo do Programa Universidade para Todos (ProUni). Entretanto, o ponto de corte de um salário mínimo e meio de renda familiar per capita inclui até o quarto quintil da classificação, de forma que não incorpora muitos estudantes de renda efetivamente mais baixa.

No ensino público, segundo o Censo da Educação Superior de 2009, o número de ingressantes por meio de processo seletivo em cursos de graduação presenciais de universidades federais saltou de 121 mil em 2001 para 208 mil em 2009. Outras ações que têm resultado no avanço em direção a uma maior oferta de vagas no ensino público e qualificado incluem a criação da Universidade Aberta do Brasil (UAB), a Universidade Virtual do Estado de São Paulo (Univesp), a implantação de novos cursos nas universidades estaduais paulistas (Unicamp, Unesp e USP) e a expansão e qualificação das Faculdades Tecnológicas (Fatecs). 
Vale destacar, entretanto, que esse aumento não é suficiente para aproximar nossos indicadores educacionais daqueles observados nos países desenvolvidos, uma vez que, segundo a Organização de Cooperação e de Desenvolvimento Econômico, OCDE (2010), apenas 11\% da população brasileira de 25 a 34 anos possui ensino superior, um valor muito inferior aos 35\% da média dos 34 países da própria OCDE.

Mesmo assim, para muitos jovens de famílias de baixa renda, a decisão quanto ao empenho de tempo e recursos financeiros para a formação profissional superior passa por muitos aspectos que tendem a pender a balança em direção ao início precoce da atividade profissional, mesmo que esta não tenha, a médio e longo prazo, as mesmas perspectivas de ascensão socioeconômica oferecidas pela formação superior. Desta forma, parece-nos adequado propor que a universidade pública crie novos instrumentos que aliem um mecanismo apropriado de seleção e ingresso a modelos de ensino e incentivo à formação superior. Tais modelos devem possibilitar que o aluno busque na formação profissional universitária sua ascensão social. Merece ser ressaltado que o novo modelo de ingresso deve aliar o seu foco principal, que é a inclusão social, ao firme compromisso com o mérito. Além disso, o novo modelo de formação geral deve seguir tendências atuais de formação multidisciplinar que tenham como objetivo maior a formação de um cidadão comprometido com a construção de uma sociedade democrática, ética e socialmente justa.

A Unicamp adotou, nos últimos anos, uma postura proativa em direção à promoção da inclusão social ao aprovar modificações no processo de seleção de alunos ingressantes. A primeira alteração, instituída em 2004, visou conferir pontuação adicional a candidatos do concurso vestibular oriundos de escolas da rede pública e que se autodeclarassem membros de minorias raciais. Criou-se, assim, uma nova modalidade de acesso aos cursos da Unicamp denominada vestibular + PAAIS (Programa de Ação Afirmativa e Inclusão Social), cujo acerto ficou comprovado pelo sucesso alcançado pelos alunos.

Projetos de inclusão são importantes para toda a sociedade e não apenas para os contemplados pelas medidas. Os estudos que precederam a implantação do PAAIS revelaram que alunos da Unicamp oriundos do ensino público apresentavam rendimento similar ou superior aos alunos oriundos do ensino privado aprovados com notas similares no vestibular. Dados atuais, disponibilizados pela Comissão Permanente para os Vestibulares da Unicamp (Comvest), revelam que alunos admitidos pela modalidade vestibular + PAAIS têm menor índice de abandono de curso e melhor rendimento acadêmico do que aqueles admitidos pela modalidade clássica de vestibular.

Desde sua implantação no vestibular de 2005, o PAAIS tem permitido o ingresso de alunos que contabilizam, em média, 30\% do número total de admissões na Unicamp, o que representa aproximadamente 1.000 alunos por ano. Considera-se que a ação teve repercussão e impactos sociais positivos, ampliando perspectivas e propiciando um ambiente favorável para discussões de novas propostas que visem ampliar o espectro social no processo de seleção de novos alunos da Unicamp. 
Apesar da inquestionável repercussão do programa PAAIS como forma de acesso que utiliza simultaneamente critérios sociais e de mérito acadêmico para selecionar alunos para a Unicamp, o número médio de egressos do ensino público que se inscrevem para os processos seletivos mantém-se em 30\%. Entretanto, os dados da Secretaria de Educação do Estado de São Paulo indicam que os egressos da escola pública correspondem a pouco mais de 70\% do total no Estado, de forma que o número de alunos que não participam do processo por iniciativa própria permanece elevado. Para o caso particular do município de Campinas, um exemplo é apresentado no Gráfico 1, que contabiliza as escolas públicas com egressos matriculados na Unicamp em 2008 e 2009. Observa-se que aproximadamente 55\% das escolas públicas da cidade não tiveram aluno matriculado na Unicamp e 20\% tiveram apenas um matriculado. Esses dados sugerem que é necessário definir e adotar outras medidas que promovam a inclusão de alunos oriundos da escola pública na universidade, motivo pelo qual a Unicamp aprovou recentemente a criação do ProFIS, um programa voltado exclusivamente a alunos egressos do ensino médio público.

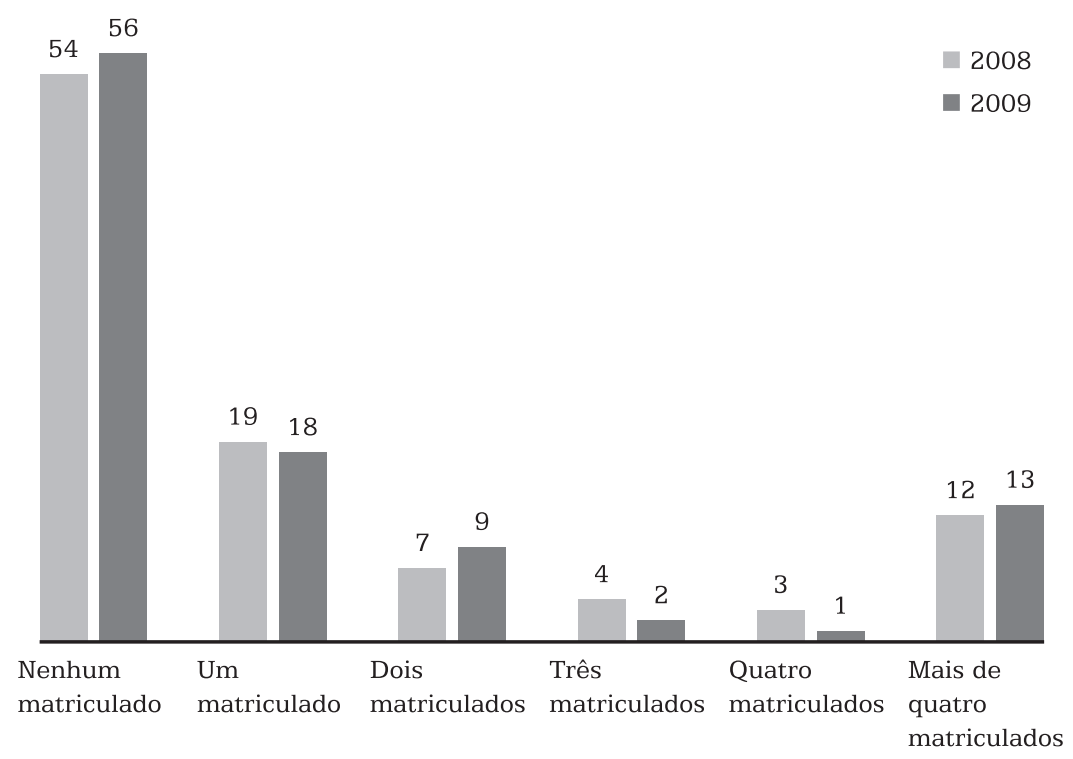

Gráfico 1 - Escolas Públicas de Campinas, segundo o Número de Ingressantes na Unicamp em 2008 e 2009

\section{A importância da formação geral}

É evidente que o conteúdo crescente nos diferentes campos do conhecimento não pode ser acomodado dentro do contexto de um programa tradicional de graduação de quatro ou cinco anos. A excelência técnica é, sem dúvida, o atributo mais importante dos graduados, mas eles também precisam ser capazes de trabalhar em equipe e ter habilidades de 
comunicação, de raciocínio lógico, de realizar análises contextuais levando em consideração questões sociais e globais e de compreender estratégias de projeto e de análise de dados. Negligenciar a formação nessas áreas privilegiando disciplinas técnicas e excluindo disciplinas das áreas de humanidades, economia, ciências políticas, comunicação e expressão e disciplinas técnicas interdisciplinares não contribui para a formação de profissionais capazes de se comunicar com o público, de se engajar no mercado global e de continuar sempre aprendendo.

Existem diversos estudos que demonstram que a formação geral tem um impacto palpável na sociedade, que vai muito além do aprendizado e desenvolvimento pessoal que ela promove. Assim, a formação geral tem sido recomendada para países em desenvolvimento por organismos como a The Task Force on Higher Education and Society (2000). A importância da educação geral inclui a formação de lideranças, cidadãos educados e trabalhadores capacitados para a indústria, o funcionalismo público, a política e a academia. Ela também promove uma consciência responsável, comportamento ético, ambição educacional, integração global e desenvolvimento profissional. É fundamental para o fortalecimento da democracia, pois procura ampliar os modos de pensar e ver o mundo, as habilidades de comunicação e o pensamento crítico.

Dentro desse contexto, têm surgido no Brasil iniciativas de uma formação universitária mais geral e abrangente, como as propostas pela Universidade Federal da Bahia (2008) e pela Universidade Federal do ABC (2006). Também nessa direção, o ProFIS se destina a formar jovens egressos do ensino médio de escolas públicas para que tenham cultura ampla, visão crítica, espírito científico, pensamento flexível e estejam preparados para o exercício da cidadania e para o mundo do trabalho.

\section{O novo curso}

O ProFIS é voltado para o desenvolvimento da capacidade de análise, domínio das habilidades de comunicação e raciocínio abstrato, conhecimento básico do mundo natural, social e artístico e do significado da cultura humana em uma visão multicultural. Procura ainda desenvolver a capacidade de solucionar problemas de forma cooperativa, desenvolver a responsabilidade cívica, social e pessoal e a capacidade para transferir conhecimento de um para outro cenário, bem como o domínio das habilidades de pesquisa quantitativa e qualitativa. "A formação geral que se pretende visa à diversidade intelectual vista como indispensável para nutrir pensamento crítico e sólidas análises das questões vivenciais e da compreensão do universo, do homem e de sua história" (Unicamp, 2010, p. 5).

O formato final do ProFIS resultou de um processo iniciado no segundo semestre de 2008 com a criação de um grupo de trabalho 
incumbido de preparar uma proposta de curso que representasse um avanço em inclusão social e inovação pedagógica. O grupo, constituído pelos professores Alcir Pecora, Elisabete Monteiro Pereira, Francisco Magalhães Gomes, Iara Lis Schiavinatto, Julio César Hadler Neto, Leandro Palermo Junior, Leandro Silva Medrano, Licio Velloso, Pascoal Pagliuso, Paulo Mazzaffera e Renato Hyuda Pedrosa, pelos acadêmicos Fernanda Cruz e Tiago Coelho de Campos e pelo diretor acadêmico Antônio Fagiani, realizou reuniões regulares entre setembro de 2009 e agosto de 2010. Nesse período, foram discutidas e definidas as diretrizes e principais características do novo curso, incluindo o perfil do aluno admitido, o método de seleção, os objetivos da formação, o perfil desejado do egresso e o modelo de migração para outros cursos. Finda a primeira etapa de trabalhos, o projeto foi apresentado e amplamente debatido em todas as unidades da universidade, recebendo críticas e sugestões que foram subsequentemente incorporadas ao projeto definitivo. No dia 9 de setembro de 2010, o ProFIS foi aprovado pelo Conselho Universitário da Unicamp, e os trabalhos para a sua implementação foram imediatamente iniciados, de forma que a primeira turma foi admitida já no início de 2011.

A seleção dos alunos do ProFIS é feita com base no desempenho alcançado pelos candidatos no Exame Nacional do Ensino Médio (Enem), garantindo a cada uma das 92 escolas públicas de Campinas no mínimo uma vaga. As vagas restantes são preenchidas seguindo a ordem de classificados no Enem e respeitando o limite máximo de dois alunos por escola.

Para ter direito ao certificado de conclusão do curso, o aluno deve obter 117 créditos, correspondentes a 1.755 horas de atividades, que devem ser cumpridas em um período de dois anos. A grade curricular é composta por 28 disciplinas obrigatórias, totalizando 109 créditos, além de 8 créditos eletivos. A Tabela 1 fornece a lista completa de disciplinas.

Apesar de o currículo do ProFIS conter uma carga horária alta, com uma média de 29,25 créditos por semestre, 40\% dos créditos correspondem a atividades práticas, desenvolvidas em salas de aula, em laboratórios ou na forma de projetos de iniciação científica. As aulas práticas e de laboratório têm por objetivo sedimentar os conhecimentos transmitidos nas aulas teóricas, sendo equiparáveis a atividades de estudo, com a orientação de um professor. Já as atividades de iniciação científica visam introduzir os alunos à pesquisa, bem como desenvolver as habilidades relacionadas à execução de um projeto individual sob a supervisão de um professor orientador. A iniciação científica contribui de forma decisiva para a formação do aluno, mesmo que ele não pretenda seguir a carreira de pesquisador, pois desenvolve a capacidade de síntese dos conceitos teóricos, de revisão bibliográfica, de experimentação prática, de redação de um relatório e de apresentação e defesa dos resultados alcançados. 
Tabela 1 - Disciplinas da Grade Curricular do ProFIS

\begin{tabular}{|c|c|c|c|}
\hline Grupo & Créditos & Disciplinas & Créditos \\
\hline \multirow{3}{*}{ Linguagens } & \multirow{3}{*}{22} & Língua inglesa I, II, III e IV & 12 \\
\hline & & Leitura e produção de texto I e II & 8 \\
\hline & & Textos fundamentais de literatura & 2 \\
\hline \multirow{6}{*}{$\begin{array}{l}\text { Ciências } \\
\text { humanas e artes }\end{array}$} & \multirow{6}{*}{20} & Comunicação, arte, cult. e sociedade & 3 \\
\hline & & Juventudes, cidadania e psicologia & 4 \\
\hline & & Introdução à história & 6 \\
\hline & & Planeta Terra & 2 \\
\hline & & Introdução à economia & 2 \\
\hline & & Ciência, tecnologia e sociedade & 3 \\
\hline \multirow{3}{*}{ Matemática } & \multirow{3}{*}{18} & Matemática básica & 6 \\
\hline & & Geometria plana e analítica & 6 \\
\hline & & Introdução à estatística & 6 \\
\hline \multirow{4}{*}{$\begin{array}{l}\text { Ciências exatas e } \\
\text { tecnologia }\end{array}$} & \multirow{4}{*}{18} & Tecnologia da informação & 4 \\
\hline & & Engenharia do ambiente & 2 \\
\hline & & Física & 6 \\
\hline & & Química & 6 \\
\hline \multirow{5}{*}{$\begin{array}{l}\text { Ciências } \\
\text { biológicas e da } \\
\text { saúde }\end{array}$} & \multirow{5}{*}{23} & $\begin{array}{l}\text { Atividade física, promoção da saúde } \\
\text { e qualidade de vida }\end{array}$ & 2 \\
\hline & & Ética e bioética & 2 \\
\hline & & Evolução & 4 \\
\hline & & O corpo humano & 2 \\
\hline & & Primeiros socorros & 3 \\
\hline $\begin{array}{l}\text { Iniciação } \\
\text { científica }\end{array}$ & 16 & $\begin{array}{l}\text { Introdução à prática de ciências e } \\
\text { artes I e II }\end{array}$ & 16 \\
\hline \multirow{2}{*}{$\begin{array}{l}\text { Outras } \\
\text { disciplinas }\end{array}$} & \multirow{2}{*}{10} & As profissões & 2 \\
\hline & & Disciplinas eletivas & 8 \\
\hline
\end{tabular}

Um dos principais objetivos do ProFIS é que os alunos concluintes permaneçam na Unicamp frequentando um de seus cursos de graduação. A maioria dos cursos de graduação da Universidade disponibilizou vagas que serão preenchidas tendo por base o desempenho dos concluintes nas disciplinas obrigatórias do programa.

Assim, ao concluírem o ProFIS, os alunos serão classificados de acordo com o Coeficiente de Rendimento das Obrigatórias (CRO), que é uma média das notas nas disciplinas obrigatórias do curso, ponderada pelo número de créditos de cada disciplina. O aluno com maior CRO escolhe sua vaga, seguido pelo segundo classificado, e assim por diante, respeitando o limite de vagas oferecidas por curso, até que todos os alunos tenham sido contemplados, o que é garantido pelo fato de existirem 120 vagas em cursos de graduação disponíveis para os alunos no ProFIS. 


\section{A primeira seleção do ProFIS}

Em 2010, o público-alvo do ProFIS era formado por cerca de 9.500 alunos matriculados no terceiro ano do ensino médio público de Campinas, ou seja, alunos que, eventualmente, poderiam ingressar no ensino superior em 2011. Entretanto, o programa foi lançado apenas em setembro de 2010, quando as inscrições para o Enem já estavam encerradas. Assim, apenas os alunos que já pretendiam fazer o exame àquela época (quer seja para ingressar em alguma universidade pública federal, quer para concorrer às bolsas do ProUni) puderam se candidatar. Com base no número de estudantes de Campinas que fizeram o Enem em 2009, estima-se que esse universo de candidatos variava de 2.200 a 2.300 jovens.

De fato, o programa teve 731 inscritos, o que corresponde a cerca de um terço dos concluintes do ensino médio que provavelmente se inscreveram no Enem. Dessa forma, havia 6,1 candidatos por vaga na seleção do ProFIS. Considerando que o programa foi lançado após o período de inscrições no Enem e com pouco tempo para divulgação, esse número foi bastante significativo.

Em 2010, o município de Campinas contava com 92 escolas públicas com alunos concluintes do ensino médio (91 escolas estaduais e a Escola Preparatória de Cadetes do Exército) e, dessas, 88 tiveram inscritos no programa. Ao final do processo de seleção, 76 (83\%) escolas tinham alunos efetivamente matriculados no ProFIS. Dos 731 inscritos, 61,4\% eram mulheres, percentual reduzido para 55,8\% quando consideramos os alunos ingressantes no curso.

As notas médias, mínimas e máximas dos inscritos e matriculados no ProFIS são dadas na Tabela 2, considerando apenas os 705 candidatos com inscrições aceitas, já que 26 foram desclassificados por terem tirado nota zero em ao menos uma prova do Enem. A média geral a que se refere a tabela é a média aritmética das notas obtidas pelo aluno nas cinco provas do Enem (linguagens, matemática, ciências da natureza, ciências humanas e redação). A classificação dos candidatos ao curso foi feita com base nessa média geral.

Tabela 2 - Notas Médias, Mínimas e Máximas de Inscritos e Matriculados no ProFIS

\begin{tabular}{|c|c|c|c|c|c|c|c|c|}
\hline \multirow{2}{*}{ Prova } & \multicolumn{2}{|c|}{ Nota Média } & \multicolumn{2}{|c|}{ Desvio Padrão } & \multicolumn{2}{|c|}{ Nota Máxima } & \multicolumn{2}{|c|}{ Nota Mínima } \\
\hline & Inscr. & Matric. & Inscr. & Matric. & Inscr. & Matric. & Inscr. & Matric. \\
\hline Média geral & 561,8 & 605,2 & 71,6 & 40,0 & 769,5 & 712,9 & 366,3 & 492,1 \\
\hline Redação & 622,1 & 682,3 & 126,7 & 110,3 & 1000,0 & 925,0 & 250,0 & 400,0 \\
\hline \multirow{5}{*}{$\begin{array}{l}\text { Média das questões } \\
\text { objetivas } \\
\text { Linguagens } \\
\text { Matemática } \\
\text { Ciências da natureza } \\
\text { Ciências humanas }\end{array}$} & 546,7 & 586,0 & 72,9 & 38,4 & 761,9 & 685,2 & 351,6 & 490,2 \\
\hline & 549,6 & 582,8 & 66,0 & 38,0 & 748,1 & 691,3 & 301,4 & 423,5 \\
\hline & 553,5 & 597,8 & 106,9 & 66,8 & 881,6 & 846,4 & 324,5 & 416,0 \\
\hline & 511,1 & 547,6 & 76,1 & 51,4 & 757,8 & 657,1 & 307,9 & 353,1 \\
\hline & 572,7 & 615,7 & 83,6 & 52,9 & 819,4 & 724,6 & 308,7 & 373,8 \\
\hline
\end{tabular}


A Tabela 2 mostra que a maioria dos candidatos ao curso tinha nota superior à média das notas do Enem, que corresponde a 500 pontos. Além disso, a nota média dos alunos matriculados no curso ficou mais de 100 pontos acima da média geral do Enem. Outro dado que chama a atenção é o alto desvio padrão das provas de matemática e redação. Esse parâmetro indica uma das dificuldades que os professores do curso enfrentarão ao lidar com a turma: a heterogeneidade da formação dos alunos.

A distribuição dos candidatos inscritos e dos alunos matriculados por grupos de nota no Enem é apresentada nos Gráficos 2 e 3. Comparando esses gráficos, observamos que o critério de seleção adotado foi bastante efetivo, reduzindo consideravelmente a concentração de alunos com nota inferior a 550.

Esse resultado é importante, pois avaliza a proposta de seleção de ao menos um candidato por escola. Se a escolha fosse feita apenas com base nas notas do Enem, poderia haver uma concentração de alunos provenientes de um grupo pequeno de escolas, como os colégios técnicos estaduais sediados em Campinas, o que impediria que se alcançasse efetivamente o propósito de inclusão social do projeto.

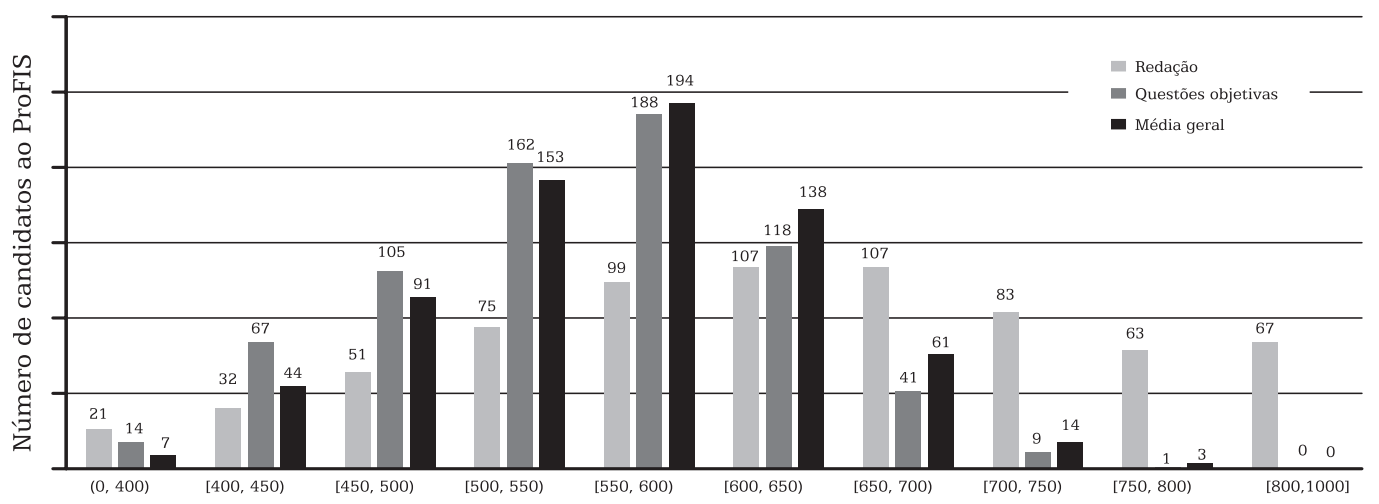

Gráfico 2 - Distribuição das Notas do Enem 2010 - Candidatos Inscritos

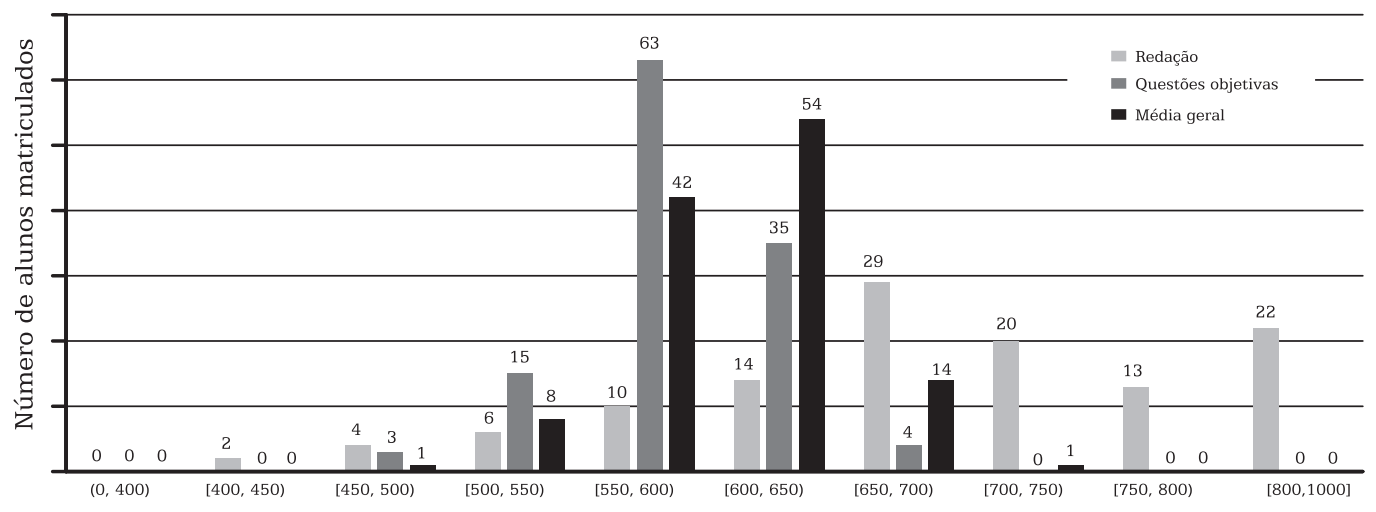

Gráfico 3 - Distribuição das Notas do Enem 2010 - Alunos Matriculados 
O Gráfico 4 permite que se tenha uma noção mais clara do desempenho dos candidatos nas quatro provas com questões objetivas do Enem. Nela se observa que, em geral, as notas de ciências humanas foram bem superiores às demais, enquanto as de ciências da natureza ficaram bem próximas da nota média do Enem. Por sua vez, as notas da prova de linguagens são bem concentradas no intervalo que vai de 550 a 650 pontos, enquanto as de matemática são as que apresentam a menor concentração, o que está em acordo com o alto desvio padrão mostrado na Tabela 2.

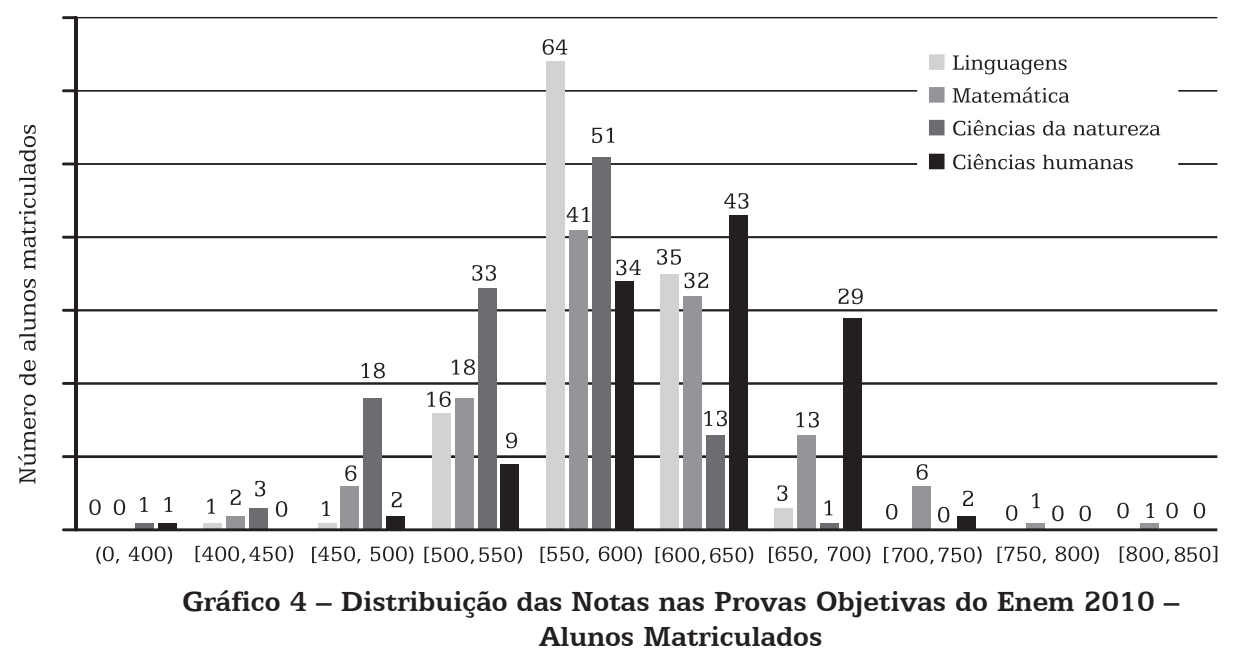

O Gráfico 5 mostra a relação entre o desempenho médio dos inscritos e matriculados no ProFIS e o desempenho médio dos alunos da mesma escola no Enem 2009. ${ }^{1}$ Apesar de o desempenho de quase todas as escolas no Enem 2009 estar situado no intervalo entre 450 e 550 pontos, com uma média bastante próxima dos 500 pontos, observa-se que, exceto em um caso, os alunos inscritos no ProFIS apresentaram um desempenho superior à media da escola. De fato, na metade dos casos, os alunos inscritos no ProFIS ficaram mais de 50 pontos acima da média da escola.

Já os alunos matriculados no curso tiveram um desempenho ainda melhor. Em 60\% dos casos, a média dos matriculados superou em mais de 100 pontos a nota média da escola e, em 85\% dos casos, a diferença foi superior a 80 pontos.

Um dos propósitos do ProFIS é permitir que ingressem na Unicamp aqueles alunos que, mesmo estudando em escolas cujas notas médias são baixas, têm bom desempenho e estão aptos a prosseguir os estudos em

${ }^{1}$ As notas médias das escolas nas provas do Enem se referem a 2009 em virtude de os dados do exame de 2010 não estarem disponíveis. No Gráfico 5, foram consideradas apenas as 52 escolas cujas médias no Enem 2009 foram divulgadas pelo Inep e que tiveram alunos matriculados no ProFIS. nível superior, mas que se autoexcluem ou são excluídos dos processos seletivos usuais das universidades públicas. O Gráfico 5 reforça a ideia de que, mesmo que o vestibular não reconheça, o potencial desses estudantes pode ser revelado selecionando-se um número mínimo de alunos por escola, como ocorreu com um ingressante do ProFIS que foi selecionado com 575 pontos, embora a nota média de sua escola no Enem não tivesse passado de 433 pontos. 


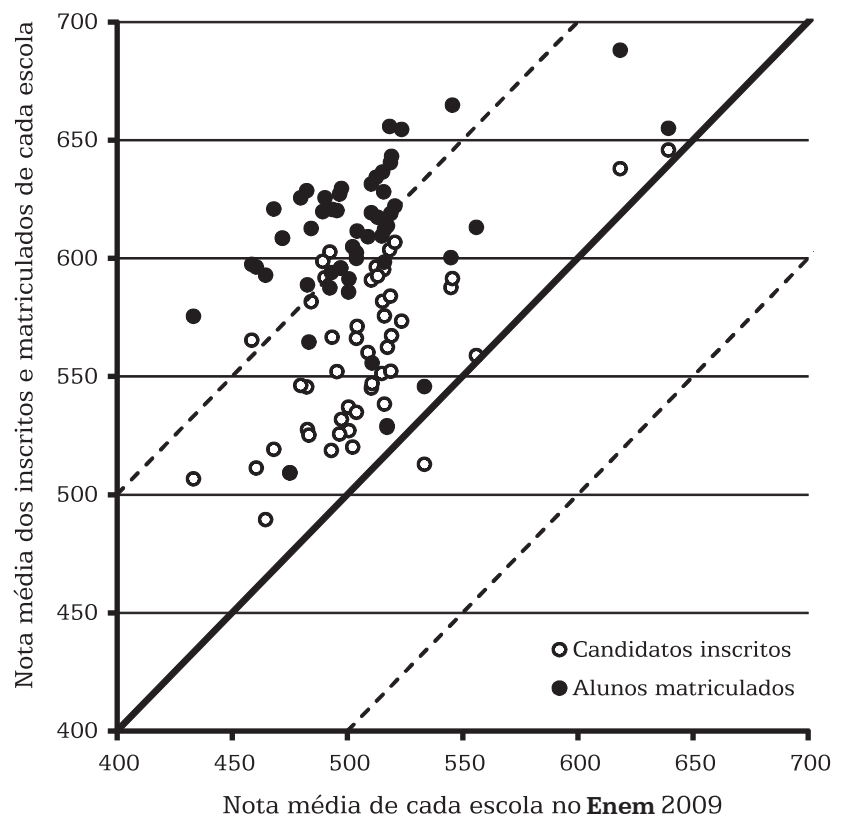

\section{Gráfico 5 - Média Geral no Enem 2010 de Inscritos e Matriculados por Escola x Média Geral da Escola no Enem 2009}

O preenchimento das 120 vagas do curso exigiu a divulgação de nove listas de chamada, que envolveram 207 convocados. Uma parte daqueles que não compareceram à matrícula havia sido aprovada em processos seletivos de outras universidades, contando, em muitos casos, com recursos do ProUni. Outras razões que levaram candidatos aprovados a não se matricularem no ProFIS incluíram o temor de ingressar em um curso que, além de ser completamente novo, tem aulas em período integral, o que os impediria de trabalhar para reforçar o orçamento familiar. Alguns candidatos, inclusive, já trabalhavam e, mesmo assumindo tarefas de baixa complexidade e mal remuneradas, relutaram em abandonar seus empregos.

Essas preocupações relacionadas ao caráter inovador do curso e à necessidade de aumentar a renda da família também foram detectadas entre os matriculados no curso, motivo pelo qual houve a preocupação de reforçar, em conversa com os pais dos ingressantes, a importância do apoio familiar à concretização dos projetos acadêmicos de seus filhos. Em paralelo, a Unicamp destinou recursos à concessão de bolsas de estudo aos alunos em dificuldades financeiras, bem como para arcar com suas despesas com o deslocamento até a universidade e com a alimentação dentro do campus. Todas essas ações têm por objetivo permitir que os estudantes se dediquem integralmente aos estudos e à vivência universitária.

\section{Aspectos socioeconômicos dos inscritos e matriculados no ProFIS}

Com o objetivo de verificar se o primeiro processo de seleção do ProFIS realmente atendeu ao propósito de inclusão social, foram coletados 
alguns dados dos alunos por meio de questionários socioeconômicos, preenchidos tanto na inscrição no programa como no momento da matrícula. Com isso, foi possível comparar o perfil dos candidatos ao ProFIS com o dos alunos inscritos e matriculados no vestibular da Unicamp e com o da população de 18 a 24 anos do Estado de São Paulo com acesso ao ensino superior. Apresentamos a seguir as informações referentes à raça/cor dos informantes, à renda mensal per capita de suas familias e ao nível de instrução dos responsáveis pelo domicílio.

O Gráfico 6 mostra a distribuição dos matriculados e dos inscritos no ProFIS e no Vestibular da Unicamp (no período 2008-2010), segundo a autodeclaração de raça/cor entre as categorias utilizadas pelo IBGE: branca, preta, parda, amarela e indígena. Observa-se que, em ambos os processos seletivos, não há diferenças significativas entre os percentuais de matriculados e de inscritos. Por outro lado, o percentual de não brancos matriculados no ProFIS (composto por pretos, pardos e indígenas) é 2,7 vezes superior ao percentual de matriculados através do vestibular.

De fato, os percentuais referentes ao vestibular da Unicamp estão próximos daqueles verificados para a população de 18 a 24 anos que teve acesso ao ensino superior no Estado. Em São Paulo, a população não branca desta faixa etária que teve acesso ao ensino superior é de apenas 18\%, enquanto os jovens classificados como brancos (que incluem brancos e amarelos) representam 82\% (IBGE, 2009).

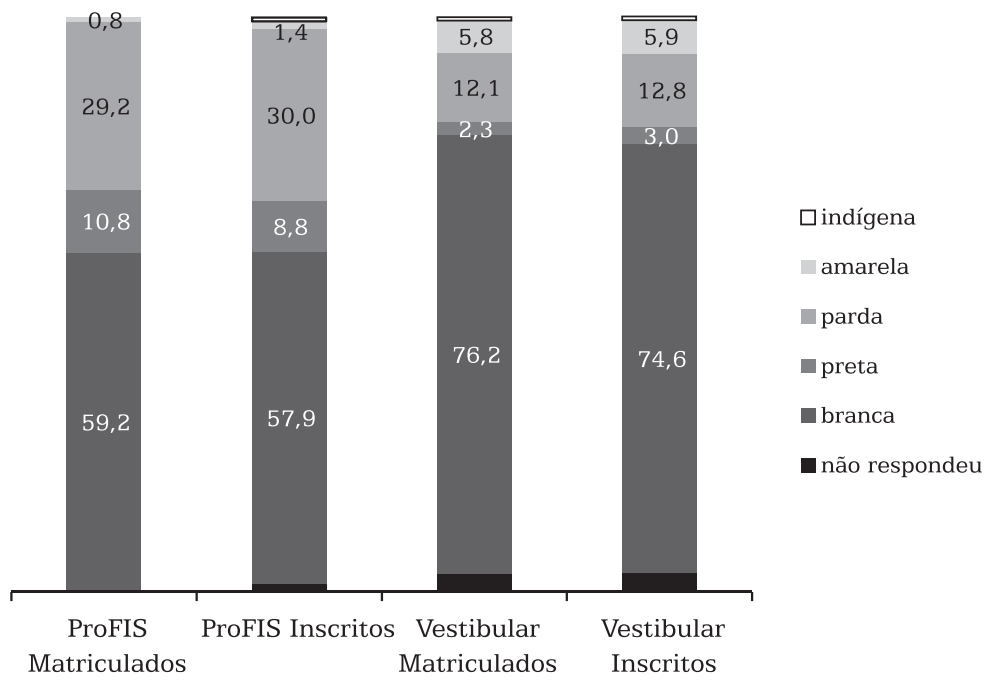

\section{Gráfico 6 - Percentuais de Inscritos e Matriculados no ProFIS e nos Vestibulares da Unicamp de 2008 a 2010, segundo a Raça/Cor Autodeclarada}

Ainda de acordo com a Pesquisa Nacional por amostra de Domicílios (Pnad 2009), a distribuição de raça/cor da população de 18 a 24 anos do Estado de São Paulo é de 64\% de brancos e 36\% de não brancos. Quando comparamos esses dados com aqueles referentes ao grupo de alunos matriculados no ProFIS, verificamos que há, no programa, um favorecimento ao grupo de não brancos, que atinge $40 \%$ do total, um percentual 
ligeiramente superior ao encontrado no Estado. Assim, apesar de ser apenas um pequeno passo, o processo de seleção do ProFIS parece capaz de contribuir para que o perfil dos alunos universitários se aproxime do observado na população do Estado de São Paulo.

As Tabelas 3 e 4, assim como o Gráfico 7, apresentam a situação econômica das famílias dos alunos inscritos e dos alunos selecionados segundo o rendimento mensal e o rendimento per capita, ou seja, a soma do rendimento de todas as pessoas da família dividida pelo número de pessoas que a compõem. Nas tabelas, a coluna $\mathrm{N}$ fornece o número de jovens que participaram de cada levantamento, e DP corresponde ao desvio padrão.

Observa-se, nesse caso, que há uma queda da renda média entre o grupo de inscritos e o grupo de alunos selecionados. Dito de outro modo, os alunos que optaram pelo programa apresentam situação econômica familiar ligeiramente inferior ao total de alunos inscritos.

Tabela 3 - Renda Mensal Familiar per Capita (R\$)

\begin{tabular}{|l|r|r|r|r|r|}
\multicolumn{1}{|c|}{ Grupo } & N & Média & DP & Mínimo & Máximo \\
\hline Matriculados no ProFIS & 115 & 492 & 304 & 61 & 2.500 \\
\hline Inscritos na seleção do ProFIS & 696 & 522 & 390 & 50 & 3.000 \\
\hline $\begin{array}{l}\text { Pop. de 18 a 24 anos com } \\
\text { acesso ao ES }\end{array}$ & 41.327 & 1.800 & 2.312 & 0 & 85.000 \\
\hline \begin{tabular}{l} 
População de 18 a 24 anos \\
\hline
\end{tabular} & 270.015 & 720 & 1.229 & 0 & 94.670 \\
\hline
\end{tabular}

Fonte: ComVest-Unicamp e Pnad 2009

Tabela 4 - Renda Mensal Familiar (R\$)

\begin{tabular}{|c|c|c|c|c|c|}
\hline Grupo & $\mathbf{N}$ & Média & DP & Mínimo & Máximo \\
\hline Matriculados no ProFIS & 116 & 1.819 & 1.199 & 300 & 10.000 \\
\hline Inscritos na seleção do ProFIS & 703 & 1949 & 1447 & 0 & 12.000 \\
\hline $\begin{array}{l}\text { Pop. de } 18 \text { a } 24 \text { anos com } \\
\text { acesso ao ES }\end{array}$ & 41.327 & 5.436 & 6.348 & 0 & 228.400 \\
\hline $\begin{array}{l}\text { População de } 18 \text { a } 24 \text { anos } \\
\text { em SP }\end{array}$ & 270.015 & 2.322 & 3.523 & 0 & 284.009 \\
\hline
\end{tabular}

Fonte: ComVest-Unicamp e Pnad 2009.

Quando os dados da população de 18 a 24 anos do Estado de São Paulo que teve acesso ao ensino superior são incluídos na comparação, chama a atenção a significativa diferença entre a média da renda mensal familiar per capita desse grupo e a dos alunos do ProFIS - matriculados ou candidatos. Como se vê, o processo de seleção do ProFIS propiciou, de fato, a inclusão de alunos com situação econômica média bastante inferior aos alunos do ensino superior do Estado de São Paulo. 


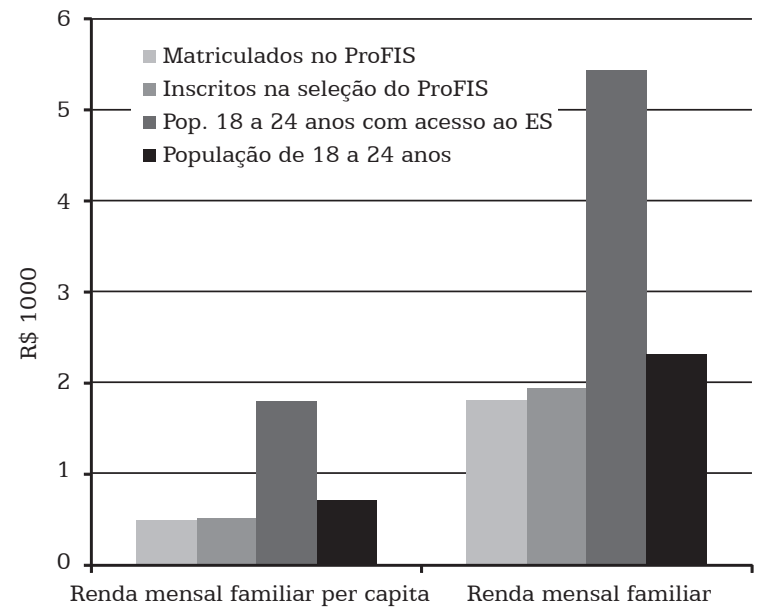

\section{Gráfico 7 - Renda Mensal Média de Matriculados e Inscritos no ProFIS e da População de 18 a 24 Anos do Estado de São Paulo}

A Tabela 3 também mostra que a renda média per capita dos candidatos ao ProFIS é 27\% inferior à da população de 18 a 24 anos do Estado de São Paulo. Se considerarmos apenas os matriculados no curso, essa diferença sobe para 31\%, o que demonstra o impacto do programa no acesso das categorias sociais de menor renda ao ensino superior.

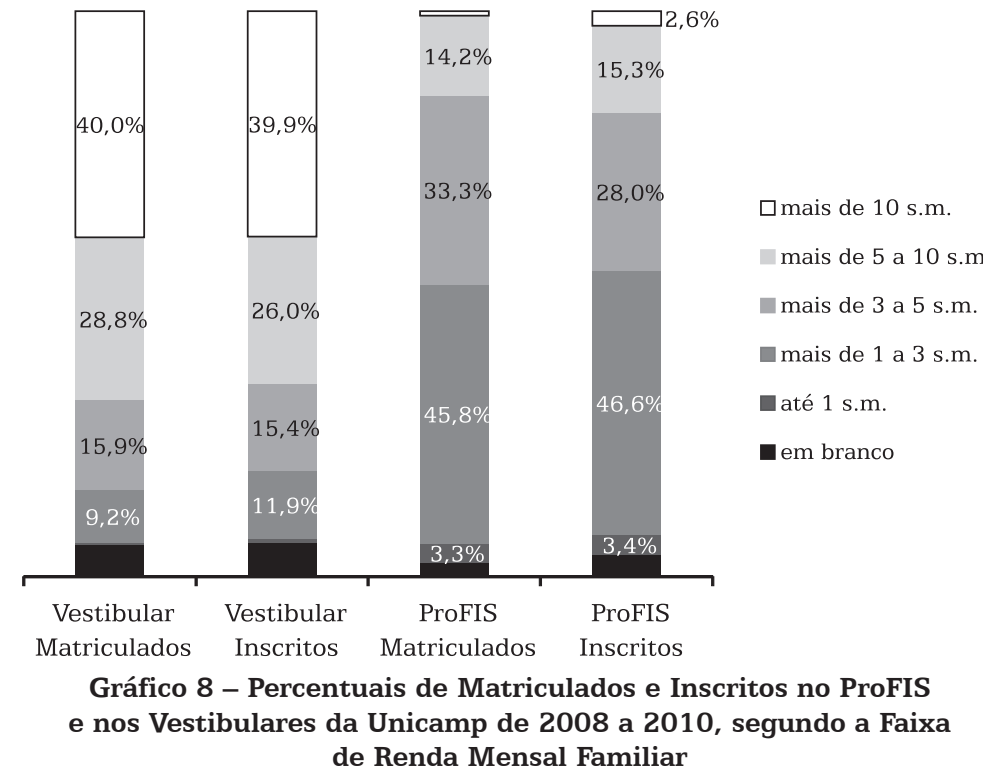

O Gráfico 8 apresenta uma comparação da renda mensal dos inscritos e matriculados no ProFIS e no vestibular da Unicamp no período de 2008 a 2010. Como se observa, as famílias com renda mensal não superior a cinco salários mínimos (s.m.) não somam 26\% do total de matriculados através do vestibular (chegando a $27 \%$ do total, se excluírmos as respostas em branco), enquanto essa faixa de renda corresponde a mais de $82 \%$ dos matriculados no ProFIS (ou 85\%, sem as respostas em branco). 
A diferença é ainda maior se nos restringirmos às famílias com renda mensal até três salários mínimos. Nesse caso, o ProFIS apresenta um percentual cinco vezes maior que o obtido pelo vestibular. Além disso, somente um matriculado no ProFIS possui renda familiar superior a 10 salários mínimos, enquanto a mesma faixa de renda corresponde a 40\% dos matriculados a partir do vestibular.

Os Gráficos 9 e 10 referem-se ao nível de instrução dos responsáveis pelos alunos, podendo ser ou não seus pais naturais. ${ }^{2}$ A distribuição observada não revela uma diferença significativa entre o grupo de alunos incritos no programa e o grupo de alunos matriculados, salvo no número das responsáveis que têm nível médio ou superior completo, faixa na qual a diferença atinge 5\%. Também se percebe que, entre os matriculados, a faixa dos responsáveis com curso superior é menor que a dos inscritos, o que é contrabalançado por um aumento da faixa que inclui aqueles que têm ensino fundamental completo.

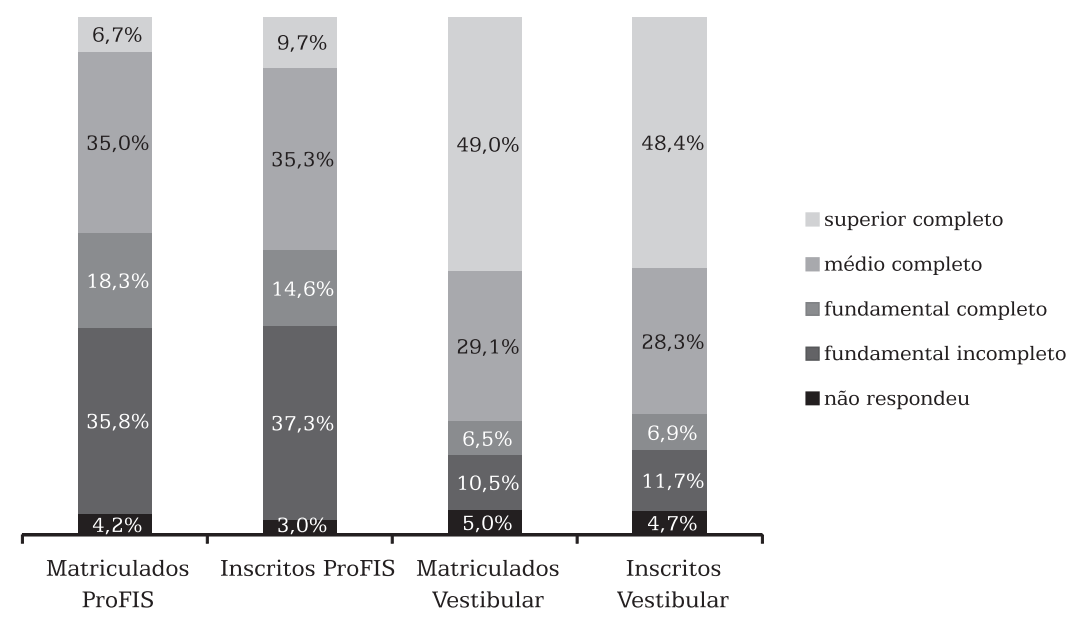

Gráfico 9 - Percentuais de Matriculados e Inscritos no ProFIS e nos Vestibulares da Unicamp de 2008 a 2010, segundo o Nível de Instrução do Responsável

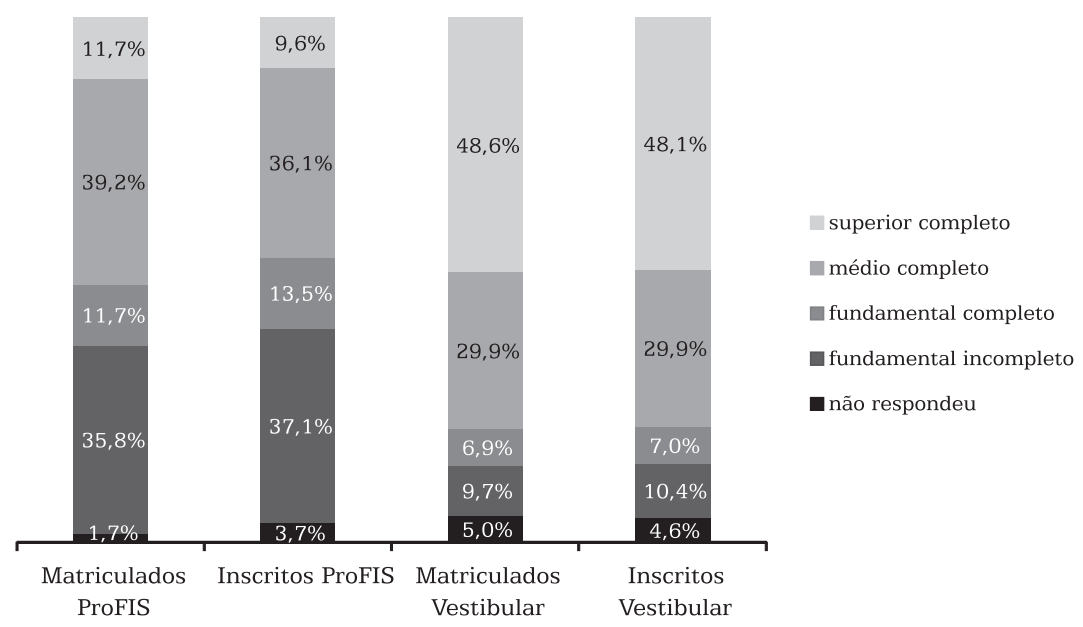

Gráfico 10 - Percentuais de Matriculados e Inscritos no ProFIS e nos Vestibulares da Unicamp de 2008 a 2010, segundo o Nível de Instrução da Responsável $\overline{{ }^{2} \text { Entre os } 119 \text { matriculados que }}$ responderam ao questionário, $54 \%$ apontaram o pai como responsável do domicílio e 39\% indicaram a mãe. 
Contudo, os dados mostram claramente que há um alto índice de alunos matriculados no ProFIS com responsáveis que não completaram o ensino fundamental e um baixo número de matriculados com responsáveis que completaram o ensino superior. Esses dados contrastam com os do vestibular, que mostram que para cerca de metade dos matriculados o responsável tem ensino superior, o mesmo acontecendo com a responsável.

Entre os alunos ingressantes no ProFIS, apenas 17 (14,2\%) têm algum responsável que concluiu o ensino superior. Percebe-se, assim, o impacto que o ingresso no programa trará a 85,8\% das famílias dos alunos do curso, para as quais essa será a primeira geração com estudantes universitários.

\section{Motivação para ingressar no curso}

O questionário aplicado no momento da matrícula continha uma questão aberta sobre a motivação para escolha do ProFIS e expectativas quanto ao curso. ${ }^{3}$ As respostas foram classificadas em 10 categorias não excludentes, sendo algumas diretamente relacionadas aos objetivos do programa (acesso à Unicamp, formação geral, apoio na escolha da carreira) e outras expectativas de desenvolvimento pessoal, intelectual e profissional. Também apareceram respostas sobre motivações que não tratam de objetivos explícitos do programa, como nivelamento com outros alunos da universidade e apoio para entrar em cursos específicos. As categorias de respostas são apresentadas no gráfico abaixo.

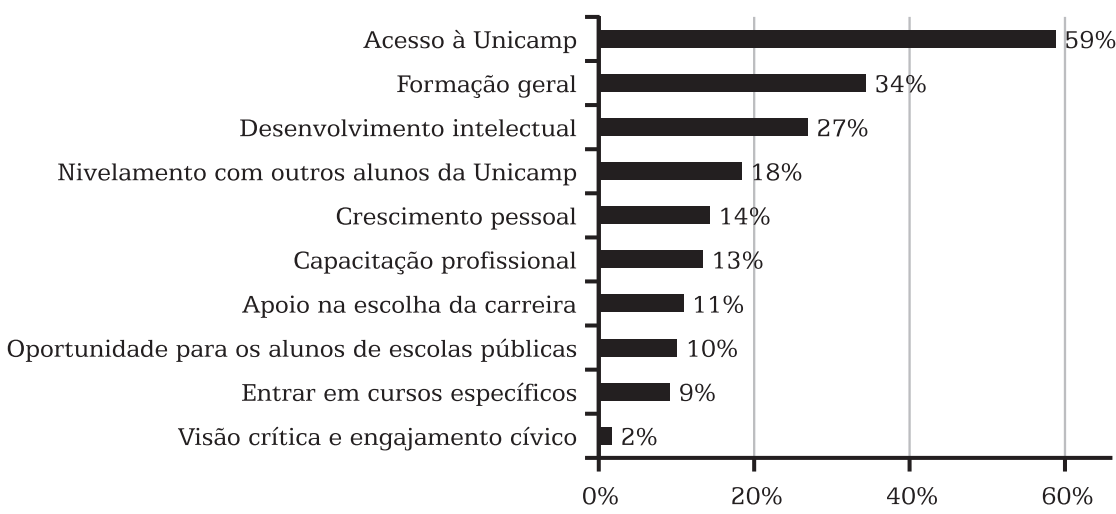

Gráfico 11 - Motivação para Cursar o ProFIS

A motivação principal para 59\% dos alunos matriculados é o acesso à Unicamp, que engloba tanto o desejo de acesso ao ProFIS, seguido de um curso de graduação, quanto à oportunidade de ingressar em uma universidade pública e de qualidade reconhecida. Para alguns alunos, esta representa a grande oportunidade de alcançar e concluir o ensino superior.

A segunda motivação mais frequente (34\%) foi o currículo de formação geral do ProFIS, entendido como oportunidade de aprimorar os conhecimentos obtidos no ensino médio pelo caráter interdisciplinar, fornecendo uma formação mais ampla para o futuro e a habilidade de
${ }^{3}$ A pergunta era: "Por que você escolheu cursar o ProFIS e quais são suas expectativas em relação ao curso?" 
aprendizado continuado ao longo da vida. Este conjunto de respostas aponta para a compreensão da natureza de educação geral do programa, que é uma novidade na Unicamp e no País.

A terceira motivação mais frequente, com $27 \%$ das respostas, diz respeito à oportunidade de desenvolvimento de habilidades intelectuais, sem ligação específica com o currículo de formação geral. Nesta categoria apareceram respostas como ampliação dos conhecimentos, acesso a novos conhecimentos e desenvolvimento intelectual. Neste mesmo sentido, $14 \%$ dos matriculados apontaram que cursar o programa representa uma oportunidade de crescimento pessoal, entendido como sair melhor do que entrou, pensando diferente e levando o aprendizado para a vida pessoal.

Ainda relacionado aos objetivos diretos do ProFIS, 10\% apontaram explicitamente a oportunidade oferecida especificamente para alunos da escola pública e $2 \%$ a possibilidade de adquirir uma visão crítica e engajamento cívico.

Chamam a atenção as motivações e expectativas que não estão diretamente relacionadas aos objetivos explícitos do ProFIS, como o nivelamento com os outros alunos da Unicamp, apontado por $18 \%$ dos matriculados, e a expectativa de capacitação profissional, apontada por $13 \%$ deles. No primeiro caso, o programa é visto como um curso que irá suprir as deficiências do ensino médio e colocar os alunos no mesmo nível dos que entraram pelo vestibular da Unicamp, ajudando posteriormente a acompanhar o curso regular com estes outros alunos.

Também chama a atenção a baixa frequência da categoria apoio à escolha da carreira (11\%), o que se explica pelo fato de a maioria já apontar quais cursos gostaria de cursar (apenas 21\% não apontaram algum curso regular de graduação ao responder à pergunta "Caso fosse escolher neste momento um curso superior, qual você escolheria?", presente no mesmo questionário).

Além disso, 9\% dos matriculados indicaram esperar que o ProFIS os ajude a entrar em cursos específicos, principalmente medicina (curso escolhido com maior frequência). Esse ponto é reforçado pela alta frequência de matriculados no ProFIS (66\%, correspondendo a 79 alunos) que prestaram vestibular em 2011, sendo 60\% deste subtotal (o equivalente a 47 alunos) na própria Unicamp.

Já a relação entre inscritos no ProFIS e no vestibular da Unicamp apresenta resultados mais modestos. Dos 731 candidatos ao ProFIS, apenas 74 (10,1\%) chegaram à segunda fase do vestibular da Unicamp. Esses candidatos eram provenientes de apenas 25 escolas (27,2\% do total). Esses dados per se indicam o grau de exclusão desses alunos dos processos seletivos de universidades públicas. Entretanto, 54 candidatos $(73,0 \%)$ foram convocados pelo vestibular ou pelo ProFIS, o que mostra o bom desempenho alcançado por esse grupo de alunos. Ao final da seleção, 27 estavam matriculados nos cursos a que se candidataram no vestibular e 9 ingressaram no ProFIS (dos 20 que foram convocados exclusivamente para esse curso).

Por outro lado, é interessante apontar que 97\% dos matriculados desejavam prosseguir seus estudos, principalmente em uma universidade pública (68\%, ou 81 alunos), antes mesmo de conhecer o ProFIS. Desses, 
a grande maioria (87\%) apontou que só poderia cursar o ensino superior se utilizasse recursos do Fies ou do ProUni.

\section{Considerações finais}

A inclusão de alunos de escolas públicas na universidade e a introdução da formação geral nos currículos de graduação são pontos que vêm sendo indicados para sanar alguns dos problemas mais graves de nosso ensino superior, quais sejam a desigualdade social e a extrema especialização e segmentação das disciplinas e dos cursos. Atacar esses dois problemas de uma só vez é o desafio que o ProFIS pretende alcançar adotando um processo seletivo e um currículo inovadores.

Os resultados apresentados acima sugerem que a parte do desafio associada à inclusão social foi atingida, já que o ProFIS conseguiu atrair um grande número de jovens provenientes de grupos sub-representados na universidade, como os pretos e pardos e as famílias de renda inferior a cinco salários mínimos. Além disso, cerca de $86 \%$ dos alunos do curso representam a primeira geração familiar no ensino superior.

Já o sucesso da adoção de um modelo de educação geral dependerá do esforço dos professores em desenvolver competências, em lugar de simplesmente transmitir conhecimentos específicos. Precisamos preparar os alunos para questionar, analisar e resolver problemas do mundo real, compreendendo o contexto histórico no qual esses problemas estão inseridos e as implicações futuras das soluções propostas. Para tanto, eles necessitarão desenvolver suas habilidades de comunicação, de coleta e organização da informação, de pesquisa e de trabalho em equipe. Alcançar esse objetivo exige o esforço contínuo de mudança de nosso modelo de ensino, cujos resultados só são mensuráveis passados vários anos.

No momento, podemos dizer apenas que o primeiro passo foi dado e que a Unicamp assumiu o compromisso de dar aos alunos o suporte necessário para que permaneçam no curso, tenham uma formação ampla e vençam o desafio de concluir um curso superior de qualidade.

\section{Referências bibliográficas}

BRASIL. Instituto Nacional de Estudos e Pesquisas Educacionais Anísio Teixeira (Inep). Resumo técnico - Censo da educação superior 2009. Brasília: Inep, 2010. Disponível em: < http://www.anaceu.org.br/ conteudo/noticias/resumo_tecnico2009.pdf $>$.

INSTITUTO BRASILEIRO DE GEOGRAFIA E ESTATÍSTICA (IBGE). Pesquisa nacional por amostra de domicílios - PNAD 2009. Rio de Janeiro: IBGE, 2009. Disponível em: < http://www.ibge.gov.br/home/ estatistica/populacao/trabalhoerendimento/pnad2009/>. 
NUNES, Edson O. As macrotendências e a realidade do ensino superior no Brasil. Rio de Janeiro: Observatório Universitário, 2011. Disponível em: < http://www.observatoriouniversitario.org.br/dados_e_tabelas_ estatisticas/macrotendencias.pdf $>$.

\section{ORGANISATION FOR ECONOMIC CO-OPERATION AND}

DEVELOPMENT (OECD) [Organização para a Cooperação e

Desenvolvimento Econômico (OCDE)]. Education at a glance 2010.

Paris: OCDE, 2010.

SCHWARTZMAN, Simon. A questão da inclusão social na universidade brasileira. In: PEIXOTO, M. C. L.; ARANHA, A. V. (Orgs.). Universidade pública e exclusão social: experiência e imaginação. Belo Horizonte: UFMG, 2008. p. 23-44.

\section{TASK FORCE ON HIGHER EDUCATION AND SOCIETY (The). Higher} education and developing countries: peril and promise. Washington, DC: The World Bank, 2000. Disponível em: < http://www.accesstosuccessafrica.eu/web/images/literature/peril_and_promise.pdf $>$.

UNIVERSIDADE FEDERAL DO ABC (UFABC). Projeto pedagógico. Santo André: UFABC, 2006. Disponível em: < http://www.ufabc.edu.br/index. php?option $=$ com_content\&view $=$ article\&id $=21 \&$ Itemid $=74>$.

UNIVERSIDADE FEDERAL DA BAHIA (UFBA). Projeto pedagógico dos bacharelados interdisciplinares. Salvador: UFBA, 2008. Disponível em: $<$ http://www.ihac.ufba.br/portugues/pdfs/projetobicompleto.pdf>.

UNIVERSIDADE ESTADUAL DE CAMPINAS (Unicamp). Projeto pedagógico do Programa de Formação Interdisciplinar Superior. Campinas: Unicamp, 2010. [Publicação interna].

Cibele Y. Andrade, doutoranda do Instituto de Economia da Unicamp, é pesquisadora do Núcleo de Estudos de Políticas Públicas (NEPP/Unicamp) desde 1986. Dedica-se à pesquisa em políticas públicas sociais na área de educação, especialmente no estudo do perfil da oferta e demanda no ensino superior no Brasil.

cyahn@terra.com.br

Francisco A. M. Gomes, doutor em Matemática Aplicada pela Unicamp, é coordenador do ProFIS e professor associado do Instituto de Matemática, Estatística e Computação Científica (IMECC) da Unicamp.

chico@ime.unicamp.br 
Programa de Formação Interdisciplinar Superior: um novo caminho

Marcelo Knobel, doutor em Física pela Unicamp, é professor titular do Instituto de Física "Gleb Wataghin" da Unicamp e pró-reitor de Graduação da universidade.

knobel@reitoria.unicamp.br

Ana Maria A. C. Silva, doutora em Política Científica e Tecnológica pela Unicamp, é pesquisadora do NEPP/Unicamp. Atualmente, coordena o projeto de avaliação do ProFIS.

anamaria@nepp.unicamp.br

Recebido em 21 de julho de 2011.

Aprovado em 18 de abril de 2012. 